\title{
Q⿻日土 \\ INTERNACIONAL \\ DE DESIGN \\ EDIÇÃO 2017 \\ Konãgxeka: o design de produção de um filme de animação indígena em Minas Gerais
}

\author{
Charles Bicalho
}

Resumo:

Relato sobre a gênese e o processo de produção do filme de animação Konãgxeka: o Dilúvio Maxakali, realizado pela produtora Pajé Filmes, sob os auspícios da sétima edição do Programa de Estímulo ao Audiovisual - Filme em Minas. Co-dirigido por mim e por Isael Maxakali, Konãgxeka se utiliza de técnicas de animação de recorte em imagens bidimensionais produzidas pelos índios Maxakali de Aldeia Verde, no município de Ladainha em Minas Gerais, para contar a versão deste povo da história tradicional do dilúvio. Universal, a narrativa do dilúvio apresenta inúmeras versões, de acordo com o povo que a representa. Falado em língua Maxakali, o filme prima pela coerência em sua visualidade, baseada nos traços, nas cores e em outras referências culturais Maxakali, preservadas graças à produção autenticamente indígena, devido à presença de artistas ilustradores, cantores, escritores, tradutores e cineastas genuinamente indígenas na equipe de produção. São destacados aspectos da direção de arte do filme que se baseiam na noção de design etnográfico ou etnodesign.

Palaviras-chave:

Filme; Animação; Produção; Design; Indígena 


\section{INTRODUÇÃO}

Pretende-se aqui traçar o percurso da produção do filme de animação Konãgxeka: o Dilúvio Maxakali, dirigido por Isael Maxakali e por mim. Tal produção se deu sob os auspícios do Programa de Estímulo ao Audiovisual - Filme em Minas. Falado em língua Maxakali, Konãgxeka é uma realização da produtora Pajé Filmes, fundada em Belo Horizonte em 2008, com o intuito de fomentar a produção de filmes indígenas. Ou seja, filmes com a participação de membros de comunidades indígenas em funções centrais da realização audiovisual, como direção e produção, ou que se inspirem em aspectos da realidade e da cultura indígenas.

\subsection{Os Maxakali, a Pajé Filmes e Isael Maxakali}

Os Maxakali, ou Tikmû'ûn - como também são chamados - são um povo indígena, cujos cerca de dois mil indivíduos vivem em quatro territórios no estado de Minas Gerais, na região sudeste do Brasil. São falantes de sua língua ancestral, o Maxakali. Caracterizam-se pela resistência em conservar os traços estruturais de sua cultura, como a língua, a religião, organização social e rituais, dentre outros.

A Pajé Filmes é uma produtora de conteúdo artístico e cultural indígena que já realizou mais de 15 filmes documentários de curta-metragem. Konãgxeka é seu primeiro filme de animação.

Em 2009 a Pajé Filmes deu início à realização da Mostra Pajé de Filmes Indígenas, um evento de divulgação da produção audiovisual indígena em nível local, nacional e internacional. Com base na exibição e no debate acerca de filmes indígenas, a Mostra Pajé já exibiu mais de uma centena de filmes dirigidos por cineastas genuinamente indígenas, ou inspirados pela realidade e cultura desses povos originários.

Isael Maxakali, que é membro-fundador da Pajé Filmes, é o cineasta indígena mineiro mais prolífico, tendo mais de vinte filmes de sua autoria, sejam produzidos pela Pajé Filmes, sejam de inciativas de outras fontes produtoras. Pela Pajé Filmes exclusivamente, Isael dirigiu mais de uma dezena de filmes.

Isael Maxakali, que é formado em Educação Intercultural Indígena pela Universidade Federal de Minas Gerais, se tornou cineasta depois das aulas de audiovisual que recebeu durante sua graduação na UFMG.

\section{KONÃGXEKA}

Konãgxeka é como os índios Maxakali designam o dilúvio em sua língua. Konãg quer dizer "água". Xeka quer dizer "grande". O mar ou oceano é também designado de konãgxeka pelos Maxakali. Konãgxeka: o Dilúvio Maxakali é, portanto, o nome dado ao filme de curta-metragem de animação produzido pela Pajé Filmes e dirigido por este autor e Isael Maxakali, para contar, de modo audiovisual, a versão Maxakali do mito do dilúvio.

\subsection{Dilúvios mundo afora}

Como afirma Hamilton A. Tyler, em Pueblo Gods and Myths, as histórias de dilúvio são universais e um dos mitos mais bem conhecidos. Tyler menciona o livro Folk Lore in the Old Testament, de James George Frazer, que apresenta variadas versões de mitos diluvianos em detalhes.

Os índios Pueblos do sudoeste dos Estados Unidos, por exemplo, apresentam uma versão da história em que a água não cai do céu em forma de chuva, mas brota de uma fonte na terra. Mais frequentemente, entre esses povos, a grande inundação é motivada por alguma forma de Cobra D'água Chifruda (Horned Water Serpent). Tyler menciona uma analogia clara entre o surgimento da humanidade, a gestação e o parto humanos, presente nessas narrativas. Do mesmo modo que o parto na água, rios que transbordam desempenham funções nas histórias do dilúvio.

Para os Laguna do Novo México, o Shipapu, uma "abertura para o mundo subterrâneo através da qual todos os Pueblos emergiram”, encheu-se com água, que ascendeu e depois baixou, sem, contudo, transbordar. Os Hopi, como os Maxakali, igualmente se utilizam de um vegetal 
(pinheiro ou junco) para se salvarem das águas em sua versão da história: "they planted a pine tree and then a reed, which brought them above the flood" (p. 110).

Para Tyler, o tema central dos mitos de dilúvio dos índios Pueblos é claramente o do sacrifício humano. Para acalmar a Cobra D'água Chifruda, um menino e um menina de seis anos de idade, "de coração puro e inocente", são ofertados à Serpente, que envolve seus corpos e mergulha na água. Na versão Maxakali, os filhotes do macaco, do porco e do veado são sacrificados pelo índio.

Também do sudoeste dos Estados Unidos, os Oraibi têm numa questão moral a causa da calamidade aquática. Na cidade de Pala'tkwabi (que seria localizada em algum lugar ao sul de Flagstaff, no Arizona, próximo ao Grand Canyon), "the people of this town were behaving very badly." Ou seja, é um mal comportamento que acarreta o castigo. Particularmente, o maltrato a um ancião teria sido a causa do castigo, como nos revela Tyler (p. 111). Na versão Maxakali é o maltrato à uma lontra. Por extensão, o desrespeito às recomendações de uma pessoa mais velha, na figura do pajé, pois este recomendara ao jovem índio pescador dar os três maiores peixes para a lontra que indicava onde estavam os cardumes no rio, possibilitando assim ao índio jogar sua rede no lugar exato e captura-los em grande quantidade. O jovem índio, no entanto, dá à lontra três pequeninos peixes, que o animal rejeita. Afastando-se para a mata, o mamífero ignora o chamado do índio para que voltasse. Analogamente, portanto, a versão Maxakali contrapõe a sabedoria e o respeito aos preceitos morais, características dos anciãos, à ignorância e o ímpeto, típicos da juventude.

Já em Tren Tren y Kai Kai Vilú (Chile, 2012), filme de Alex Moya que retrata uma versão diluviana dos índios Mapuche, Kai Kai Vilú é a serpente do mar que derrete o gelo dos Andes, desencadeando a inundação. "Los mapuce ya no compartían ni vivían en comunidad. El egoísmo, la envidia y la agresión entre ellos y el ixofijmogen/diversidad de vidas era lo que imperaba en cada lofce/comunidad", conta o texto presente no site de promoção do filme (8300 Web, 2016). Já na produção Xeg Xeg ka Kay Kay (Chile, 2010), da produtora Fluorfilmes, os rios e mares saem de seus leitos para inundar todo o território Mapuche.

\section{PRÉ-PRODUÇÃO: VERSÕES E CONVERSAÇÕES MAXAKALI}

Algumas versões da história do dilúvio Maxakali já haviam sido publicadas em livros produzidos pelos próprios índios. O livro que conta histórias de antigamente (1998) e Penãhã (2005) são dois livros Maxakali que trazem versões da história. Bilíngues, tais obras são fruto do trabalho de gravação e transcrição da versão oral da história em língua maxakali contada por algum representante do povo Tikmû'ûn, falante da língua. Para o filme Konãgxeka, foi feita a gravação de nova versão da história, contada por Isael Maxakali, sua esposa, Sueli Maxakali, e Elizângela Maxakali. Depois da transcrição, realizada em Belo Horizonte pelos próprios contadores, traduziu-se para o português, com minha ajuda. Com base nesta tradução foi realizada a roteirização da história em 2012. Já em fase de produção, no entanto, quando nos encontrávamos na Aldeia Verde para a oficina de ilustração do projeto, gravamos ainda uma outra versão da história, motivada por sugestões de acréscimo e correção de aspectos da história feitas pelo pajé Totó. Delcida, mãe de Isael Maxakali, Noêmia, mãe de Sueli Maxakali, também estavam presentes e participaram desta última versão, auxiliando na rememoração de detalhes do enredo.

Esta última versão foi posteriormente transcrita em Belo Horizonte e traduzida ao português. Foi desta versão que retiramos as falas dos diálogos do filme. As mesmas serviram de base à tradução para o espanhol e o inglês.

Durante o período de pré-produção, Isael foi levado ao cinema para assistir a Noé (2014), devido à semelhança de temas. Assistimos a uma versão em 3D. Foi a primeira experiência de Isael com o cinema tridimensional. Ele dizia ter gostado da experiência. Ao sair da sala de exibição, disse que Noé é um pajé, pois conversa com os bichos. E que as crianças da aldeia gostariam de assistir ao filme. Assim que pude, comprei uma cópia em DVD do filme e dei a ele. Isael disse também ter tido ideias para o Konãgxeka, como, por exemplo, mostrar a Pedra da Ladainha no filme. A Pedra da Ladainha, também conhecida como Marta Rocha, é uma enorme rocha visível de qualquer ponto da cidade de Ladainha, localizada no Vale do Mucuri, norte de Minas Gerais. A Pedra tornou-se o símbolo da cidade, cujo município preserva matas exuberantes ao seu redor. Desde 2006 Ladainha conta com uma reserva Maxakali, onde vive Isael, com aproximadamente 300 habitantes. 
O projeto para o filme foi enviado para o edital Filme em Minas no ano de 2014. Aprovado, teve início a produção no começo de 2015.

\section{PRODUÇÃO}

\subsection{Oficina de ilustração}

Em julho de 2015, a equipe da Pajé Filmes, composta por mim, pelo diretor de animação do projeto e por outro produtor, se deslocou de Belo Horizonte até a Aldeia Verde Maxakali, no município de Ladainha, em Minas Gerais, onde foi realizada uma oficina de ilustração com os membros maxakalis da equipe: Isael, Sueli, Elizângela. Outros Maxakali acabaram participando da oficina: Cassiano (filho de Isael), Gilberto, Maiza e Paulinho.

O diretor de animação Jackson Abacatu coordenou a oficina. Foi pedido aos participantes que realizassem desenhos com base na história de Konãgxeka. Assim, os Maxakali desenharam os personagens da história, como o pajé, sua esposa, o índio jovem, a lontra, o macaco, o porco e a corça. Também foram solicitados desenhos de alguns elementos do cenário da narrativa. Para a criação dos desenhos foram utilizados lápis de cor, canetas hidrocores e tintas. Tudo foi feito sobre folhas de papel A4.

O abundante material produzido pelos Maxakali na oficina foi levado a Belo Horizonte, para que Jackson pudesse escanear, retocar e recortar para, então, se utilizando de programas de tratamento de imagem e animação, como Photoshop e After Effects, manipulá-los, criando a ilusão de movimento típico de um filme de animação. Animação de recorte digital, com tratamento digital sobre desenhos manuais, compõem a técnica básica utilizada.

\subsection{Direção de arte indígena}

Em Design e linguagem cinematográfica - narrativa visual e projeto, Ludmila Ayres Machado considera que "cinema e design são consequências do projeto da modernidade, e os fundamentos da linguagem de ambos têm a mesma origem" (p. 71). A autora lembra ainda que "tanto o cinema quanto o design basearam-se, em parte, nos mesmos princípios visuais já propostos pela pintura. Todas essas formas de representação trabalham a transposição do espaço real, que é onde vivemos, a um espaço plástico, que é o da superfície da imagem" (ibidem).

Já em Arte em cena - a direção de arte no cinema brasileiro, Vera Hamburger afirma:

Artista multidisciplinar, o diretor de arte lida com matérias plásticas e arquitetônicas elaborando uma linguagem específica de cada projeto. Delineia relações visuais entre a figura posta em cena, os objetos e o espaço na composição de quadros bidimensionais, em movimento e dotados de voz própria, intrinsecamente ligados à dramaturgia. $\mathrm{O}$ diretor de arte é um pesquisador dos elementos que compõem a expressividade visual, atento a cada detalhe da construção da imagem, tanto no que diz respeito a sua dinâmica interna quanto à visualização de sua edição em sequência (p. 52).

Foi com o espírito imbuído das concepções acima mencionadas, e mais a inspiração dada pela presença e a arte indígena, que a equipe de realização de Konãgxeka trabalhou. Por exemplo, diante da questão de como se mostrar no filme o acasalamento entre homem e animais que a história sugere, Jackson Abacatu criou graficamente uma espécie de altar para figurar a ação. As colunas de grafismos encimadas por chamas e as silhuetas dos personagens sugerem que algo acontece por trás de um véu. Do mesmo modo, o sacrifício dos animais: é retratada simbolicamente, ritualisticamente. 

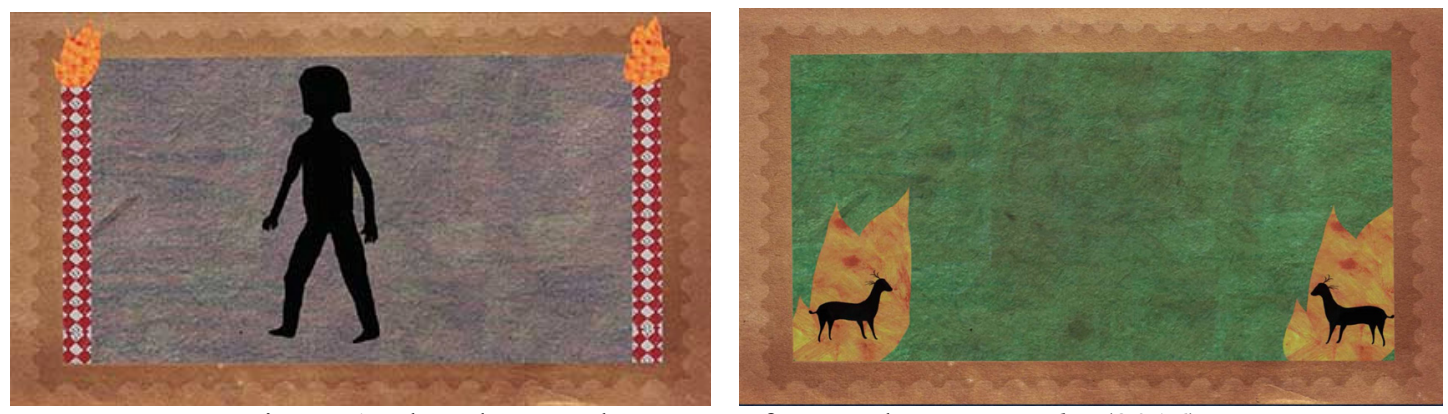

Figura 1: altar do acasalamento - frames de Konãgxeka (2016).

Na sequência, para simbolizar o intercurso sexual, Jackson criou uma mandala com os personagens girando em fusão no centro, sugerindo a união visceral entre eles. A solução foge do realismo ao trabalhar com elementos gráficos tipicamente maxakalis.

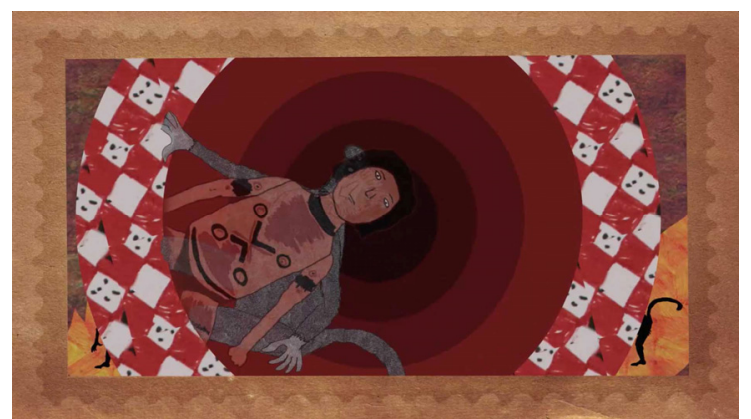

Figura 2: mandala da cópula - frame de Konãgxeka (2016).

\subsubsection{Grafismos indígenas}

Em seu clássico livro Grafismo indígena - estudos de antropologia estética, Lux Vidal afirma que

o homem ocidental tende a julgar as artes dos povos indígenas como se pertencessem à ordem de um Éden perdido. Dessa forma, deixa de captar, usufruir e incluir no contexto das artes contemporâneas, em pé de igualdade, manifestações estéticas de grande beleza e profundo significado humano (p. 13).

Nossa intenção foi desfazer tal concepção. Buscamos, neste projeto, tratar a produção artística dos Maxakali como o que de falto ela é: viva e atual. Quisemos dar ao filme uma identidade Maxakali e percebemos que só alcançaríamos tal intuito agindo com naturalidade quanto ao traço original de seus desenhos. À parte não indígena da equipe de produção do filme ficou a tarefa de contribuir com o know how e a tecnologia para a realização daquilo que é necessário para transformar desenhos estáticos (uma prática a que os Maxakali já estão muito acostumados) em um desenho animado.

Seguindo sugestões de Isael Maxakali e sua esposa Sueli, ficou a cargo de Jackson Abacatu a criação dos grafismos a ilustrar as pinturas corporais para se criar uma identidade visual de cada personagem do filme. Foram escolhidos os grafismos que ajudam a diferenciá-los um do outro.
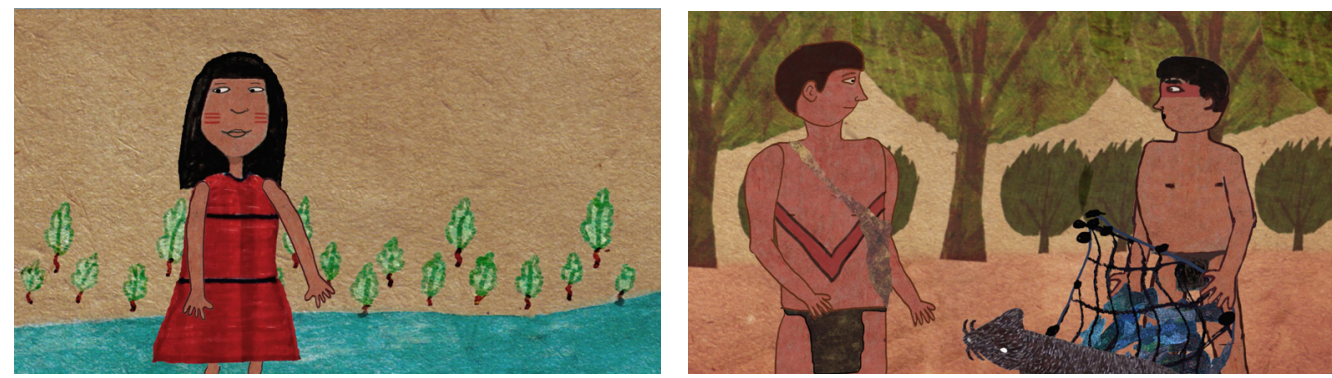

Figura 3: pintura corporal dos personagens - frames de Konãgxeka (2016) 
Assim, o índio jovem, o pajé e sua esposa, cada um tem um grafismo que o identifica: a esposa do pajé traz traços duplos na; o pajé ostenta uma pintura sólida em torno aos olhos; e o índio jovem se identifica por uma pintura em "v" sobre o tronco. Como afirma ainda Vidal a respeito da expressão gráfica indígena:

Apenas recentemente a pintura, a arte gráfica e os ornamentos do corpo passaram a ser considerados como material visual que exprime a concepção tribal de pessoa humana, a categorização social e material e outras mensagens referentes à ordem cósmica. Em resumo, manifestações simbólicas e estéticas centrais para a compreensão da vida em sociedade (p. 13).

Vale lembrar, a propósito da direção da arte, o que escreve Vera Hamburger:

a experiência da elaboração audiovisual é complexa. O que conduz naturalmente o espectador a diferentes sensações ou emoções é objeto de rigorosa construção, fruto de trabalho coletivo, em que o diretor de arte tem papel relevante, ao conferir identidade visual à obra, contribuir com a formação de atmosferas visuais distintas em cada cena ou passagem, imprimir características plásticas marcantes a cada personagem e cenário (p 53).

\subsection{Eisenstein, Da Vinci e os Maxakali: decupando o dilúvio}

O cineasta russo Sergei Eisenstein, em seu artigo "Palavra e imagem"1, cita, como exemplo de um "roteiro de filmagem", as notas de Leonardo Da Vinci para uma representação pictórica do dilúvio. Para Eisenstein, na descrição de Da Vinci, "a cena audiovisual do Dilúvio é apresentada com uma clareza incomum." Tal clareza se apoia em um "movimento bastante definido", que perfaria, como identificado por Eisenstein, uma espécie de ciclo das imagens, saindo de um ponto e retornando a ele, em termos criativos:

Começando com uma descrição dos céus, o quadro termina com uma descrição semelhante, mas consideravelmente intensificada. No centro está o grupo de seres humanos e suas experiências; a cena se desenvolve dos céus para os homens, e dos homens para os céus, passando pelos animais. Os detalhes maiores (os primeiros planos) são encontrados no centro, no clímax da descrição (p. 27).

Impressionado pelo trabalho do mestre renascentista, Eisenstein escreve ainda:

Inquestionavelmente, a descrição extraordinariamente sequencial de Leonardo cumpre não apenas a tarefa de enumerar os detalhes, mas a de traçar a trajetória do futuro movimento sobre a superfície da tela. Aqui vemos um exemplo brilhante de como, na aparentemente estática 'coexistência' simultânea de detalhes, num quadro imóvel, ainda foi aplicada exatamente a mesma seleção de montagem, existe exatamente a mesma sucessão ordenada na justaposição de detalhes, como nas artes que incluem o fator tempo (p. 28).

Em Konãgxeka tomamos a descrição de Da Vinci como mote para a nossa sequência do dilúvio. E, de Eisenstein, o método. O modo de Leonardo Da Vinci vai de encontro à proposta de Eisenstein no que tange à criação de imagens. Para o cineasta russo, apresentar uma sequência de "representações parciais" é a melhor maneira de se criar uma imagem convincente na mente do espectador:

A tarefa com a qual ele se defronta é transformar esta imagem em algumas representações parciais básicas que, em sua combinação e justaposição, evocarão na consciência e nos

\footnotetext{
1 EISENSTEIN, Sergei. O sentido do filme. Tradução de Teresa Ottoni. Rio de Janeiro: Jorge Zahar, 2002, (pp. 13-50).
} 
sentimentos do espectador, leitor ou ouvinte a mesma imagem geral inicial que originalmente pairou diante do artista criador (p. 28).
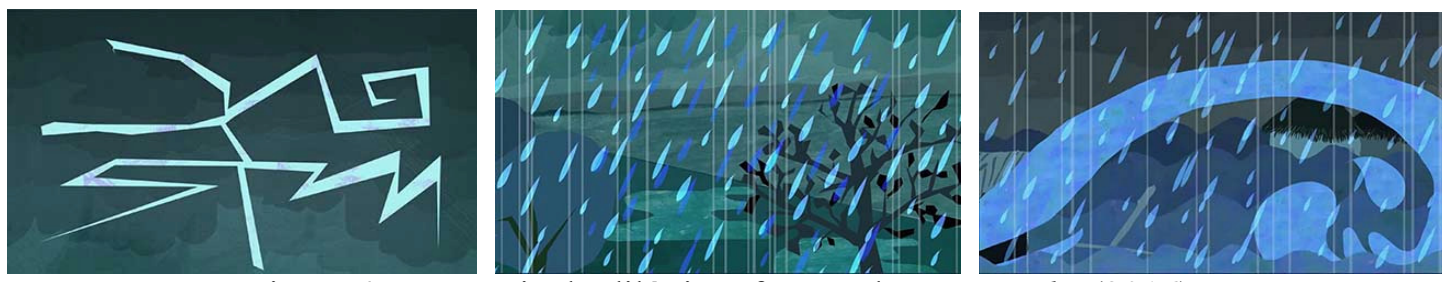

Figura 4: sequência do dilúvio - frames de Konãgxeka (2016).

É curioso notar a semelhança entre a análise de Eisenstein e a estratégia de que os próprios índios Maxakali se valem para representar suas histórias. Utilizando-se de procedimento afim ao que descreve o cineasta russo, os Maxakali, em nível de oralidade, também apresentam um modo de projeção de imagens que ilustram suas histórias. Como demonstro em Koxuk - a imagem do yãmîy na poética Maxakali (2010), nos seus rituais, chamados yãmîyxop, os Maxakali apresentam cantos, bastante descritivos, que correspondem a projeções de cenas que ilustram suas narrativas, tamanho o grau de suas sínteses imagísticas. A cantoria em tais rituais funciona como ilustrações cantadas de cenas e passagens que compõem suas narrativas. Seria através desses cantos que os índios apresentam suas "representações parciais básicas", de que fala Eisenstein. Justapostas e combinadas através dos cantos nos rituais, tais "imagens" evocam na consciência do participante do ritual a imagem geral da história que lhe subjaz (BICALHO, 2010)2.

\subsection{Câmera subjetiva e perspectivismo}

Um pormenor a se notar na decupagem é a intenção de criar um enquadramento que sugerisse a subjetiva de um peixe num plano subaquático. Nele, a rede do índio pescador é enquadrada.

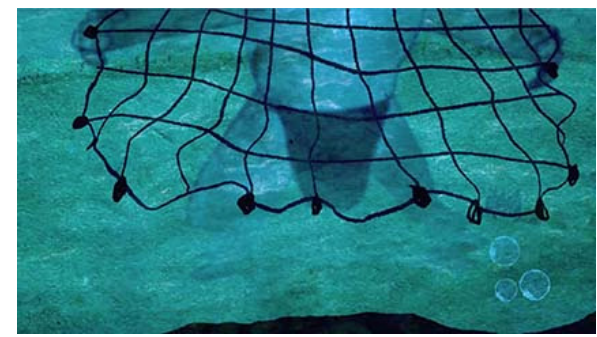

Figura 5: subjetiva do peixe - frame de Konãgxeka (2016).

Tal enquadramento é simbólico das decisões de decupagem do filme, uma vez que a intenção de dar subjetividade ao peixe acarreta proporcionar "pessoalidade" ao mesmo. Tal procedimento é significativo, uma vez que de um modo geral os ameríndios e sua visão de mundo dada por sua filosofia e religião consideram os animais praticamente como seus iguais. $\mathrm{O}$ antropólogo Viveiros de Castro e sua noção de perpectivismo deixa claro:

Em suma, os animais são gente, ou se vêem como pessoas. Tal concepção está quase sempre associada à ideia de que a forma manifesta de cada espécie é um envoltório (uma 'roupa') a esconder uma forma interna humana, normalmente visível apenas aos olhos da própria espécie ou de certos seres transespecíficos, como os xamãs (pp. 227-8).

Como quer Viveiros ainda, "essa forma interna é o espírito do animal: uma intencionalidade ou subjetividade formalmente idêntica à consciência humana, materializável, digamos assim, em um esquema corporal humano oculto sob a máscara animal" (p. 228). No caso Maxakali, seus espíritos yãmîy podem ser tomados como uma expressão do perspectivismo. É através deles, animais e demais

\footnotetext{
2 Conferir, sobretudo, a seção "Iluminuras cantadas" (pp. 129-150) no Capítulo II.
} 
elementos da natureza que os circundam, sobretudo no bioma da Mata Atlântica, em que tal povo costuma habitar, que se revela o conhecimento do mundo.

\section{PóS-PRODUÇÃO: ETNODESIGN}

\subsection{Design sonoro: vozes e cantos}

$\mathrm{Na}$ fase de pós-produção, quando detalhes de finalização da obra são ajustados, Isael manifestou preocupação com a possibilidade de as crianças da aldeia virem a reconhecer as vozes (incluindo a sua própria) emprestadas aos personagens do filme. Na pós-produção então foram acrescentados efeitos e tratamentos para descaracterizar as vozes reais.

Tal preocupação de Isael se coaduna com a dos pajés maxakalis de um modo geral, no que se refere a filmagens na aldeia: eles não permitem que se enquadrem os participantes dos rituais em close; provavelmente para que não se reconheça, através de algum detalhe do rosto, o "ator" por trás da máscara. No filme Xupapoynãg (2011), de Isael Maxakali, em que os homens da aldeia estão paramentados com lama e tecidos a cobrirem-lhes o corpo, para que se passem por lontras, em determinado momento ouve-se uma mulher, em meio à batalha travada contra os "animais", a exclamar: "Não pode tirar a máscara!" Pois não se pode revelar a identidade do participante do ritual. Não se pode quebrar a magia do espetáculo.

Depois de escolhidos com Isael, Sueli e Elizângela, quais cantos tradicionais maxakalis sonorizariam as passagens da história, eles foram gravados em Belo Horizonte. Para os ruídos e outros sons do filme foram utilizados sites que disponibilizam bancos de dados gratuitamente.

\subsection{Identidade visual indígena}

Como escreve Jan-Christopher Horak em Saul Bass - anatomy of film design, "film credit sequences utilize words and images, so there is a relationship between typography and visual design" (p. 90). Despois ele se pergunta: "What is the nature of that relationship, and why do designers choose one particular typographic style or font over another?" (ibidem) Pergunta semelhante foi feita pela equipe de produção de Konãgxeka no que se refere à criação da identidade visual no processo de finalização e pós-produção. Todo o trabalho artístico da Pajé Filmes é de fato pautado por tal orientação. Cada obra tem sua identidade visual baseada na arte gráfica indígena. Em outro momento já explicitamos isso: "Pajé Filmes: a presença de um design indígena mineiro na mídia", artigo escrito em co-autoria por mim e Isael Maxakali, está publicado nos anais do $1^{\circ}$ Colóquio Nacional de Design, que aconteceu em setembro de 2011 na Escola de Design da Universidade do Estado de Minas Gerais (UEMG), em Belo Horizonte. Como afirmo no artigo,

iniciou-se uma produção intensa de livros, cartilhas, filmes e outros, com vistas a dar espaço ao modo de ser diferenciado de cada tradição indígena ainda sobrevivente em território brasileiro. Nos cursos, portanto, visando a publicação midiática são oferecidas aulas e oficinas de editoração de livros, filmagem e edição de vídeo, pintura, literatura, entre outras formas artísticas. Essa produção já acumula atualmente um montante significativo e traz uma visão diferente daquela que se costumava ter sobre as populações indígenas, além de questões estéticas inovadoras, graças à força de sua expressão (p. 257).

Tentávamos sugerir a existência de uma gestalt indígena, pois "muito frequentemente dotada de simetria e esbanjando geometrismos, a arte gráfica ameríndia no geral compartilha de um sentido de equilíbrio e distribuição dos elementos no espaço" (p. 259). Em outro momento chamo a atenção para o "capricho gráfico" já nos manuscritos das produções livrescas indígenas:

Estaria nesse capricho gráfico do manuscrito a força do hábito artesanal da mão indígena. A escrita, como qualquer desenho, pressupõe a organização de elementos sobre uma superfície. A distribuição ou disposição de objetos semióticos sobre o papel, no que compõe um grafismo, seguiria a mesma lógica da pintura sobre a pele, tradicional suporte para o traço indígena (p. 261). 
Portanto, na produção gráfica de capa, rótulo, cartazes e outras peças referentes ao filme, preservam-se as características da identidade artística tipicamente Maxakali, como suas cores recorrentes (vermelho, preto e branco), seus elementos geométricos e outros.
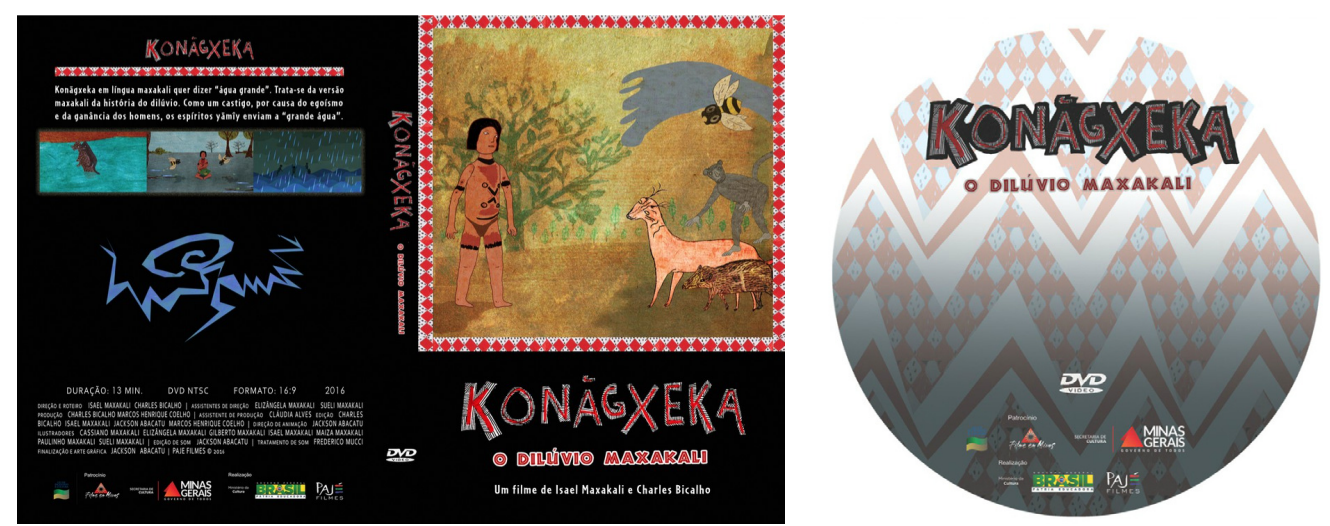

Figura 6: capa e rótulo para o DVD do filme Konãgxeka (2016).

Foram criadas também duas versões para o cartaz de divulgação do filme. Um deles se aproveita da imagem presente na capa do DVD. O outro se utiliza da imagem de um dos personagens do filme para ilustrar a peça.
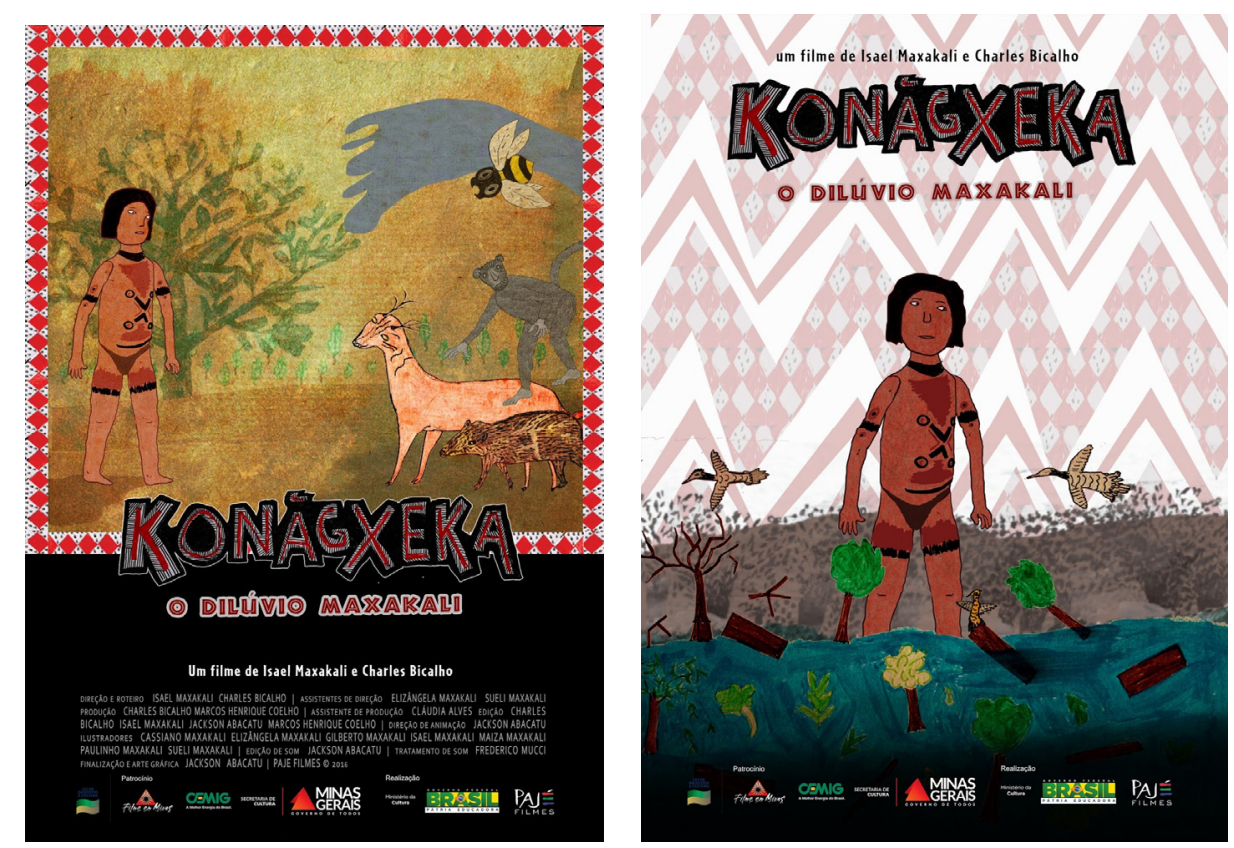

Figura 7: cartazes para o filme Konãgxeka (2016).

Especificamente sobre a produção audiovisual da Pajé Filmes, destaco a importância de se preservar a originalidade dos desenhistas indígenas na produção gráfica dos DVDs: "Vemos a presença de elementos da arte indígena no leiaute das capas de DVD. Os desenhos feitos por Isael, Sueli Maxakali, ou outros, são digitalizados e aproveitados na composição pelos artistas gráficos" (p. 266).

Tudo isso nos leva à noção de Etnodesign, tal como exposta por Mário Santiago em seu "Manifesto por um Etnodesign" (2002). A noção de Etnodesign englobaria, dentre suas possibilidades, o "estudo das diferentes formas, linguagens e manifestações de design que emitem as diferentes formações culturais" e a "valorização das tradições e das especificidades culturais, com base nos conceitos de alteridade e multiculturalismo" (p. 2).

Tais procedimentos, como concluo no artigo do Colóquio, "propicia a sobrevivência da cultura indígena nos meios de comunicação, fazendo com que as vozes, as imagens, mensagens e tradições indígenas sobrevivam no mundo midiático da atualidade" (p. 269). 


\section{CONCLUSÃO}

Após a finalização do filme, fizemos seu lançamento na V Mostra Pajé de Filmes Indígenas, que ocorreu no Sesc Palladium, em Belo Horizonte, de 19 a 24 de abril de 2016. Aproveitamos a ocasião, pois um dos três eixos que compuseram esta edição da Mostra Pajé foi justamente uma Retrospectiva Isael Maxakali, em que sete filmes do cineasta indígena foram exibidos, incluindo seu mais novo filme e primeira animação, Konãgxeka.

Konãgxeka: o Dilúvio Maxakali é um importante marco, tanto na carreira de Isael Maxakali, quanto na minha, quanto na trajetória da Pajé Filmes, pois é o primeiro trabalho em animação, depois de uma produção considerável de documentários. A técnica da animação se mostrou muito propícia ao intuito que a equipe de produção tinha de contar uma história que, de outro modo, se mostraria irrealizável, devido ao fato de conter aspectos tão grandiosos quanto o cataclismo de seu tema. Em filmagem live action, por exemplo, como seria possível, a uma produção de baixíssimo orçamento como essa, realizar a façanha de mostrar em tela as vicissitudes de tal história? A técnica de animação de recorte de desenhos manuais, com tratamento digital, se mostrou eficaz e natural, devido à familiaridade que todos temos, em maior ou menor grau, com os desenhos manuais. O dilúvio serve inclusive de metáfora para a dimensão de possibilidades que o filme de animação oferece para a expressão artística.

\section{Konãgxeka: design production of an indigenous animated film in Minas Gerais}

Abstract: Account of the genesis and production process of an animated film called Konãgxeka: the Maxakali Flood, held of Pajé Filmes producer under the auspices of the seventh edition of the Filme em Minas, a stimulus to audiovisual program of Minas Gerais state government. Co-directed by this author and indigenous filmmaker Isael Maxakali, Konãgxeka uses cutout animation techniques in twodimensional images produced by members of Maxakali Indian Community of Aldeia Verde (Green Village), located in the municipality of Ladainha, in Minas Gerais, Brazil. The film tells the Maxakali version of flood legend. Spoken in Maxakali language, the film strives for consistency in its visuality, based on features, colors and other cultural references, preserved thanks to authentically indigenous production due to the Maxakali indigenous presence of illustrator artists, singers, writers, translators and genuinely indigenous filmmakers in the production team. The aspects of prodution design of the film, which is based on the notion of ethnographic design or etnodesign, are highlighted.

Keywords: Film; Cartoon; Production; Design; Indigenous

\section{Referências bibliográficas}

BICALHO, Charles. Koxuk: a imagem do yãmîy na poética maxakali. Tese de Doutorado na Faculdade de Letras da UFMG, 2010.

Pajé Filmes: a presença de um design indígena mineiro na mídia. In: Anais do I Colóquio Internacional de Design, Belo Horizonte, 2011. (pp. 256-270)

EISENSTEIN, Sergei. 0 sentido do filme. Tradução de Teresa Ottoni. Rio de Janeiro: Jorge Zahar, 2002.

FLUORFILMS. 2010. Xex Xeg ka Kay Kay. 02 min. Disponível em <https://www.youtube.com/watch?v=UtOQIW9LDj0> Acessado em 10 de maio de 2016. 
HAMBURGER, Vera. Arte em cena: a direção de arte no cinema brasileiro. São Paulo: Senac; Sesc, 2014.

HORAK, Jan-Christopher. Saul Bass: anatomy of film design. Lexington: University Press of Kentucky, 2014.

MACHADO, Ludmila Ayres. Design e linguagem cinematográfica - narrativa visual e projeto. São Paulo: Blucher, 2011.

MAXAKALI, Isael. 2011. Xupapoynãg. Belo Horizonte: Pajé Filmes. DVD, 14 min.

MOYA, Alex. 2012. Tren Tren y Kai Kai Vilú. 04 min. Disponível em <https://vimeo.com/57710774> Acessado em 10 de maio de 2016.

SANTIAGO, Mário. 2002. Manifesto por um Etnodesign. Disponível em: <http://www.mariosantiago.net/Textos\%20em\%20

PDF/Manifesto\%20por\%20um\%20Etnodesign.pdf> Acessado em 27 de abril de 2016.

TYLER, Hamilton A. Pueblo Gods and Myths. Norman: University of Oklahoma Press, 1964.

VIDAL, Lux. (org.) Grafismo indígena - estudos de antropologia estética. São Paulo: Studio Nobel; Fapesp; Edusp, 1992.

VIVEIROS DE CASTRO, Eduardo. Perspectivismo e multinaturalismo na América indígena. Disponível

em:

<http://www.oquenosfazpensar.com/adm/uploads/artigo/perspectivismo_e_multipluralismo_na_ameri ca_indigena/n18EduardoViveiros.pdf> Acessado em 12 de maio de 2016.

8300 Web - Cooperativa de Trabajo por la Comunicación. Epew xeg xeg y kay kay. La cosmovisión mapuce. Disponível em: <http://www.8300.com.ar/2009/07/15/xeg-xeg-y-kay-kay-lacosmovision-mapuce/> Acessado em 15 de maio de 2016. 